\title{
Genetic heterogeneity of feed intake, energy-corrected milk, and body weight across lactation in primiparous Holstein, Nordic Red, and Jersey cows
}

\author{
B. Li, ${ }^{\prime} \dagger^{1}$ W. F. Fikse, ${ }^{*}$ P. Løvendahl, $\dagger$ J. Lassen, $†$ M. H. Lidauer, $\ddagger$ P. Mäntysaari, $\ddagger$ and B. Berglund ${ }^{*}$ \\ *Department of Animal Breeding and Genetics, Swedish University of Agricultural Sciences, SE-750 07 Uppsala, Sweden \\ †Department of Molecular Biology and Genetics, Aarhus University, DK-8830 Tjele, Denmark \\ $\ddagger$ Natural Resources Institute Finland (Luke), Production Systems, FI-31600 Jokioinen, Finland
}

\begin{abstract}
In this study, we aimed to estimate and compare the genetic parameters of dry matter intake (DMI), energycorrected milk (ECM), and body weight (BW) as 3 feed efficiency-related traits across lactation in 3 dairy cattle breeds (Holstein, Nordic Red, and Jersey). The analyses were based on weekly records of DMI, ECM, and BW per cow across lactation for 842 primiparous Holstein cows, 746 primiparous Nordic Red cows, and 378 primiparous Jersey cows. A random regression model was applied to estimate variance components and genetic parameters for DMI, ECM, and BW in each lactation week within each breed. Phenotypic means of DMI, ECM, and BW observations across lactation showed to be in very similar patterns between breeds, whereas breed differences lay in the average level of DMI, ECM, and BW. Generally, for all studied breeds, the heritability for DMI ranged from 0.2 to 0.4 across lactation and was in a range similar to the heritability for ECM. The heritability for BW ranged from 0.4 to 0.6 across lactation, higher than the heritability for DMI or ECM. Among the studied breeds, the heritability estimates for DMI shared a very similar range between breeds, whereas the heritability estimates for ECM tended to be different between breeds. For BW, the heritability estimates also tended to follow a similar range between breeds. Among the studied traits, the genetic variance and heritability for DMI varied across lactation, and the genetic correlations between DMI at different lactation stages were less than unity, indicating a genetic heterogeneity of feed intake across lactation in dairy cattle. In contrast, BW was the most genetically consistent trait across lactation, where BW among all lactation weeks was highly correlated. Genetic correlations
\end{abstract}

Received February 19, 2018.

Accepted June 25, 2018.

${ }^{1}$ Corresponding author: bingjie.li@slu.se between DMI, ECM, and BW changed across lactation, especially in early lactation. Energy-corrected milk had a low genetic correlation with both DMI and BW at the beginning of lactation, whereas ECM was highly correlated with DMI in mid and late lactation. Based on our results, genetic heterogeneity of DMI, ECM, and BW across lactation generally was observed in all studied dairy breeds, especially for DMI, which should be carefully considered for the recording strategy of these traits. The genetic correlations between DMI, ECM, and BW changed across lactation and followed similar patterns between breeds.

Key words: feed efficiency, dairy cattle, genetic parameter, genetic heterogeneity, breed difference

\section{INTRODUCTION}

The widely recognized genetic variation in feed efficiency (FE) has opened up possibilities for genetically improving the $\mathrm{FE}$ of dairy cattle to increase the profitability of dairy production and to reduce the ecological footprint. In the interest of including $\mathrm{FE}$ in breeding goals, genetic parameters for FE-related traits, as the important "toolbox" to initiate selection, have recently been studied in several dairy cattle populations worldwide (e.g., Liinamo et al., 2012; Berry et al., 2014; Manzanilla-Pech et al., 2016). Some consensus has been reached among the studies in genetic variation and genetic parameters for $\mathrm{FE}$, whereas potential differences between breeds, parities, and even different lactation stages have also been reported (Spurlock et al., 2012; Manzanilla Pech et al., 2014b; Li et al., 2016).

Two key questions have been widely discussed in previous studies of the genetic parameters of FE-related traits in dairy cattle. The first question focused on the genetic variation and heritability of FE-related traits. From recent studies, the DMI of dairy cows, as the key component of all available FE traits in dairy cattle, was reported with moderate heritability that could vary across lactation (e.g., Koenen and Veerkamp, 1998; Manzanilla Pech et al., 2014b; Li et al., 2016). The 
potential genetic heterogeneity of feed intake across lactation stages has been observed, where feed intake between early and middle lactation was found to be in low or even negative genetic correlation (Buttchereit et al., 2011; Manzanilla Pech et al., 2014b; Tetens et al., 2014). The second question focused on the genetic relationships between feed intake and production or functional traits to draw a picture of the correlated responses and to assess indicator traits for FE. In Holstein cows, the genetic correlation between feed intake and milk production was shown to change across lactation, with a positive correlation at mid and late lactation but a low or even negative correlation in early lactation (Hüttmann et al., 2009; Buttchereit et al., 2011; Liinamo et al., 2012; Manzanilla Pech et al., 2014b). The genetic correlation between feed intake and BW was also shown to vary across lactation in Holstein cows (Veerkamp and Thompson, 1999; Spurlock et al., 2012; Manzanilla Pech et al., 2014b). Findings from recent studies have reached some consensus for the answers to these key questions. However, it remains a challenge to obtain accurate or detailed estimates across lactation, primarily due to the constraint of data sizes or lack of records across the entire lactation.

Another challenge is obtaining sufficient genetic information in non-Holstein populations for FE. Studies of the genetics of FE in the 1980s demonstrated between-breeds or selection-line variation in feed intake as the first impression of genetic differences in feed consumption (Korver, 1988). Over the years, due to considerable genetic progress, the results from old studies may no longer be fully relevant to modern dairy populations of high genetic merit (Liinamo et al., 2012). Recent genetic studies of FE have mostly focused on Holstein cows (e.g., Berry et al., 2014; de Haas et al., 2015). Breeds other than Holstein (e.g., Jersey and Nordic Red, RDC) are economically important breeds globally and locally and may have important genetic value with respect to FE. Good knowledge of the genetic parameters for FE-related traits in multiple dairy breeds would benefit diverse selection purposes in dairy production (e.g., genetic evaluation and improvement of different breeds, across-breeds genomic evaluation).

The breeding and feeding systems are similar among research herds in Nordic countries. For this study, we combined FE-related data across lactation from research herds in Denmark, Finland, and Sweden for 3 dairy breeds (Holstein, RDC, and Jersey). The objectives of this study were to estimate and compare the genetic parameters of DMI, ECM, and BW across first lactation in 3 dairy breeds. In addition, genetic correlations between DMI, ECM, and BW were estimated across lactation in these dairy breeds.

\section{MATERIALS AND METHODS}

\section{Animals, Feeding, and Data Recording}

Cows in our study were from 6 research herds from Denmark, Finland, and Sweden comprising 3 dairy breeds: Holstein, RDC, and Jersey. The research herds were located at the Danish Cattle Research Center (DCRC, Foulum) and the Ammitsbøl Skovgaard research herd (Skovgaard, Vejle) in Denmark, at the Natural Resources Institute Finland past research herd (Rehtijärvi, Jokioinen) and current research herd (Minkiö, Jokioinen) in Finland, and at the Swedish University of Agricultural Sciences research herd (Kungsängen, Uppsala) and Öjebyn research herd (Öjebyn) in Sweden. The studied cows calved between 1991 and 2015 for Holstein cows, between 1994 and 2015 for RDC cows, and between 1995 and 2015 for Jersey cows. Pedigree information was extracted from the Nordic Cattle Genetic Evaluation (NAV, Skejby, Denmark) database by tracing back as many generations as possible for cows with records. The cows studied by Li et al. $(2016,2017)$ were part of the data in this study.

The cows were involved in several nutrition experiments within research herds. The feeding information in the trials has been described in detail in previous studies (Mäntysaari et al., 2003, 2012; Nielsen et al., 2003; Løvendahl et al., 2010; Løvendahl and Chagunda, 2011; Mäntysaari and Mäntysaari, 2015; Byskov et al., 2017). Feed offered to cows and feed refusals were measured individually to calculate the feed intake per cow. The DM contents in TMR and concentrates were analyzed regularly, and the compositions were aligned and merged with feed intake records to obtain daily DMI values per cow. A weekly average DMI per cow was calculated as the average of daily DMI records in each lactation week.

Milking and milk yield recordings were described in previous studies (Mäntysaari et al., 2003, 2012; Nielsen et al., 2003; Løvendahl et al., 2010; Løvendahl and Chagunda, 2011; Mäntysaari and Mäntysaari, 2015; Byskov et al., 2017; Li et al., 2017). A weekly observation of average daily milk yield per cow was obtained from the average of daily milk yield records per cow in each week. Milk samples were taken regularly for analyses of fat, protein, and lactose content (Mäntysaari et al., 2003, 2012; Løvendahl et al., 2010). The average daily ECM $(\mathrm{kg})$ per cow in each lactation week was calculated from average daily milk yield $(\mathrm{kg})$ and milk composition $(\mathrm{g} /$ $\mathrm{kg}$ ) using the formula by Sjaunja et al. (1990): ECM $(\mathrm{kg})=$ milk yield $(\mathrm{kg}) \times\{[38.30 \times$ fat content $(\mathrm{g} / \mathrm{kg})$ $+24.20 \times$ protein content $(\mathrm{g} / \mathrm{kg})+16.54 \times$ lactose content $(\mathrm{g} / \mathrm{kg})+20.7] / 3,140\}$. Cows were weighed on a 
weekly basis in some research herds. In other research herds cows were automatically weighed at each milking so that BW records were averaged to obtain a weekly record of BW per cow in each week (Mäntysaari et al., 2003, 2012; Nielsen et al., 2003; Løvendahl et al., 2010; Mäntysaari and Mäntysaari, 2015; Li et al., 2017).

\section{Data Editing}

The original data set consisted of 160,488 weekly records of DMI, ECM, and BW across lactation for 2,720 dairy cows across breeds and parities. From the original data set, primiparous Holstein, RDC, and Jersey cows were extracted for the current study. For Holsteins and Jerseys, cows' weekly records from lactation wk 1 to 44 were included in the analyses, corresponding to the typical 305-d lactation. For RDC, cows' weekly records from lactation wk 1 to 32 were studied due to sparse records in later lactation weeks in some research herds. Cows with fewer than 4 weekly records of DMI, ECM, and BW during the studied lactation periods were removed from the data set. A few cows with a calving age of more than 38 mo at first calving were also removed from the data set. The age at first calving ranged from 24 to $38 \mathrm{mo}, 25$ to $38 \mathrm{mo}$, and 24 to $36 \mathrm{mo}$ for Holstein, RDC, and Jersey cows, respectively. After data editing, a total of 30,717 records of 842 primiparous Holstein cows from 3 research herds in Denmark and Sweden (DCRC, Skovgaard, and Öjebyn herds), 21,279 records of 746 primiparous RDC cows from 5 research herds from all 3 countries (Rehtijärvi, Minkiö, Kungsängen, DCRC, and Skovgaard herds), and 14,021 records of 378 primiparous Jersey cows from 2 research herds in Denmark (DCRC and Skovgaard herds) were included in the statistical analyses. Cows were recorded with weekly records of DMI, ECM, and BW across lactation (Table 1).

\section{Statistical Analyses}

The analyses were carried out separately for each breed. Within each breed, variance components for weekly observations of DMI, ECM, and BW across lactation were estimated using the following random regression model for each trait:

$\mathrm{y}_{\mathrm{jklmp}}=\mathrm{u}+$ Herd-Trial $_{\mathrm{j}}+\mathrm{CA}_{\mathrm{k}}+\mathrm{YSC}_{\mathrm{l}}+$ Lactwk $_{\mathrm{m}}$

$+\sum_{\mathrm{n}=0}^{2} \mathrm{a}_{\mathrm{np}} \phi_{\mathrm{n}}+\sum_{\mathrm{n}=0}^{2} \mathrm{pe}_{\mathrm{np}} \phi_{\mathrm{n}}+\mathrm{e}_{\mathrm{jklmp}}$,

where $y_{\text {jklmp }}$ is the weekly observation of DMI, ECM, or BW in lactation week (Lactwk) $m$ for cow $p$, where cow $\mathrm{p}$ is in herd and trial (Herd-Trial) $\mathrm{j}$ at calving age
(CA) $\mathrm{k}$ and in the year-season of calving (YSC) $\mathrm{l}$; $\mathrm{u}$ is the intercept for DMI, ECM, or BW; Herd-Trial ${ }_{\mathrm{j}}$ is the fixed effect of herd and trial for the cow; the trials were herd-specific, and some Herd-Trial ${ }_{j}$ could be shared across breeds ( $\mathrm{j}=1$ to 29 for Holstein cows; $\mathrm{j}=$ 1 to 16 for RDC cows; $j=1$ to 14 for Jersey cows); $\mathrm{CA}_{k}$ is the fixed effect of calving age in months, where the calving age of Holstein, RDC, and Jersey cows ranged from 24 to 38,25 to 38 , and 24 to 36 mo, respectively; $\mathrm{YSC}_{1}$ is the fixed effect of year-season of calving, where 4 seasons were defined (March to May, June to August, September to November, and December to February; $l=1$ to 22 for Holstein cows, $1=1$ to 45 for RDC cows, and $l=1$ to 39 for Jersey cows); and Lactwk $\mathrm{m}_{\mathrm{m}}$ accounts for the fixed effect of lactation week $(\mathrm{m}=$ 1 to 44 for Holstein and Jersey cows; $m=1$ to 32 for RDC cows). Random regression terms were used to describe the cows' additive genetic effect and permanent environmental effect. The $\mathrm{a}_{\mathrm{np}}$ and $\mathrm{pe}_{\mathrm{np}}$ are the nth regression coefficients of the Legendre polynomial for the random additive genetic effect and the random permanent environmental effect, respectively, for cow p; and $\phi_{\mathrm{n}}$ is the nth covariable of the second-order Legendre polynomial for the week of lactation. The analyses failed to converge when higher order polynomials were fitted for animal and permanent environmental effects; $\mathrm{e}_{\mathrm{jklmp}}$ is the random residual, which was assumed to have heterogeneous variances across lactation (every 4 consecutive lactation weeks was set as 1 class).

The variance components were estimated by an average information-restricted maximum likelihood algorithm (Jensen et al., 1997) implemented in the software DMU (Madsen and Jensen, 2013). Within each breed, estimates of variance components were used to calculate heritability for DMI, ECM, and BW for each trait in each lactation week. Genetic correlations for each

Table 1. Descriptive statistics of DMI, ECM, and BW for 842 primiparous Holstein (HOL) cows in 44 lactation weeks, 746 primiparous Nordic Red cows (RDC) in 32 lactation weeks, and 378 primiparous Jersey (JER) cows in 44 lactation weeks

\begin{tabular}{lcccc}
\hline Item & Mean & SD & Minimum & Maximum \\
\hline DMI (kg/d) & & & & \\
HOL & 19.4 & 3.2 & 3.8 & 40.9 \\
RDC & 18.5 & 3.3 & 4.1 & 39.1 \\
JER & 15.8 & 2.9 & 5.5 & 34.5 \\
ECM (kg/d) & & & & \\
HOL & 29.1 & 6.0 & 1.2 & 57.9 \\
RDC & 26.9 & 5.5 & 1.6 & 49.0 \\
JER & 24.6 & 5.3 & 2.8 & 48.6 \\
BW (kg) & & & & \\
HOL & 601.2 & 63.8 & 387.0 & 869.0 \\
RDC & 575.1 & 61.0 & 396.0 & 857.5 \\
JER & 433.0 & 47.9 & 253.5 & 630.7 \\
\hline
\end{tabular}


trait between different lactation weeks were calculated for DMI, ECM, and BW across lactation.

In addition, genetic correlations between DMI, ECM, and $\mathrm{BW}$ at the same lactation week were estimated in Holstein and RDC cows using bivariate analyses by applying the same random regression model as for single trait analyses. The bivariate analyses between DMI,
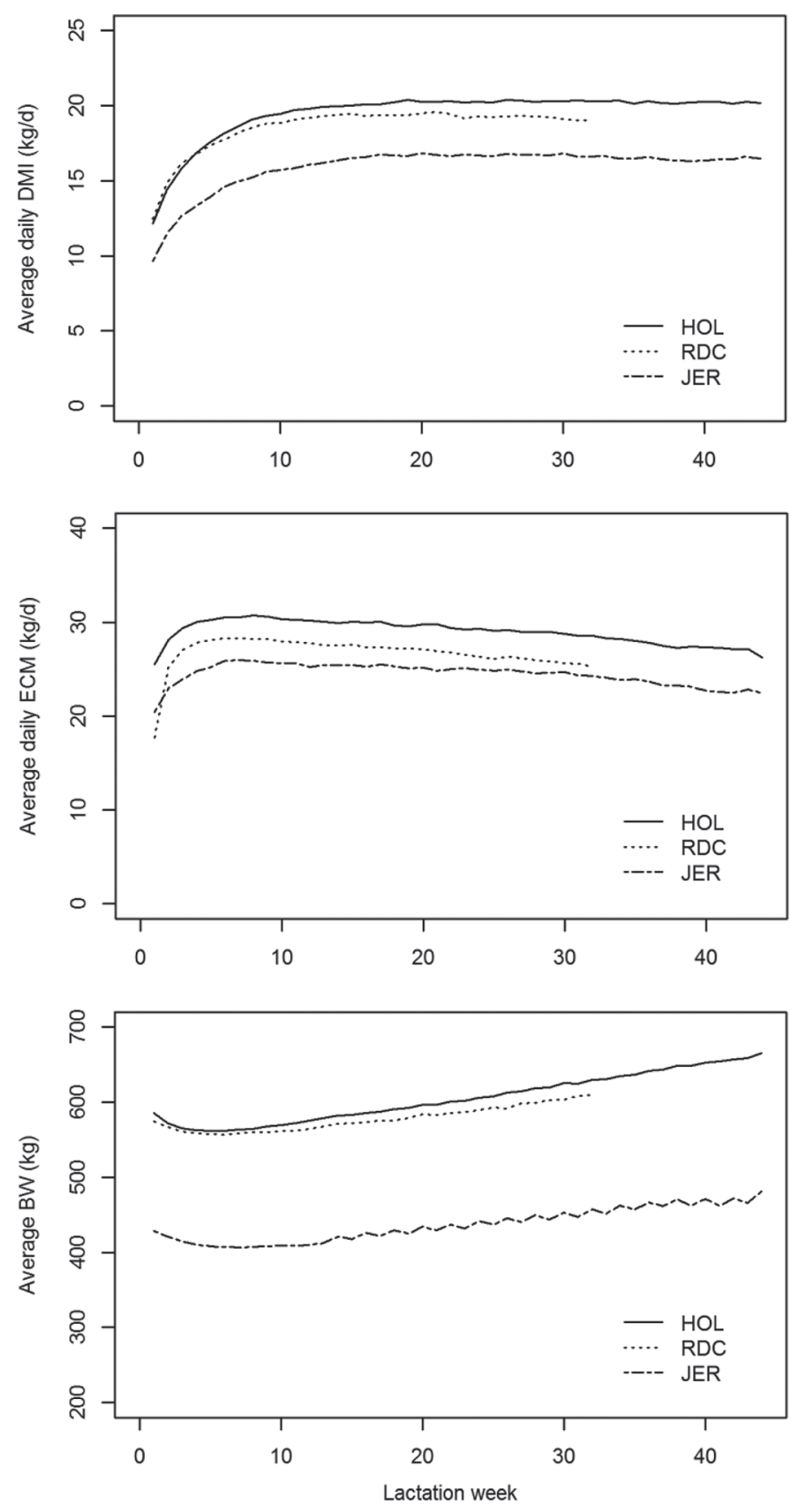

Figure 1. Phenotypic means of daily DMI, daily ECM, and BW for Holstein cows (HOL) in 44 lactation weeks, Nordic Red cows (RDC) in 32 lactation weeks, and Jersey cows (JER) in 44 lactation weeks.
ECM, and BW were not performed for Jersey cows due to the small amount of data available.

\section{RESULTS}

\section{Phenotypic Means of DMI, ECM, and BW in Holstein, $R D C$, and Jersey Cows}

Cows of different breeds followed a similar pattern of phenotypic means of daily DMI over lactation, and the breed difference was in the level of phenotypic means (Figure 1). Generally, the average daily DMI in all 3 breeds increased from the beginning of lactation until reaching a relatively steady level not earlier than lactation wk 11. Holstein cows had the highest level of average daily DMI among the 3 breeds, and Jersey cows had the lowest level of DMI. More specifically, the average daily DMI of Holstein cows increased from 12.1 $\mathrm{kg} / \mathrm{d}$ (in wk 1) to $20.0 \mathrm{~kg} / \mathrm{d}$ (in wk 14) and remained quite constant afterward. The RDC cows had an average daily DMI similar to Holstein cows at the beginning of lactation $(12.5 \mathrm{~kg} / \mathrm{d}$ in wk 1) but tended to have lower DMI than Holstein cows afterward.

The pattern of average daily ECM over the course of lactation was similar in 3 breeds (Figure 1). The ECM yield increased in early lactation and peaked in wk 7 (for RDC and Jersey cows) or wk 8 (for Holstein cows), followed by a gradual decrease in yield. Among the 3 breeds, Holsteins and Jerseys had the highest and lowest levels of average daily ECM over lactation, respectively.

As for BW, Holstein and RDC cows had a similar level of average BW compared with Jersey cows, which had a significantly lower level (Figure 1). Loss of BW occurred at the beginning of lactation in all 3 breeds, and the nadir of the BW curve appeared in wk 5 in Holstein cows, in wk 6 in RDC cows, and in wk 7 in Jersey cows. The total loss of BW from wk 1 to the nadir was on average $23.4,17.1$, and $22.1 \mathrm{~kg}$ for Holstein, RDC, and Jersey cows, respectively. After the nadir point, the cows' BW were regained gradually to the original level of BW (i.e., BW in wk 1) in wk 16 for all breeds and followed by continuous BW gains. After the nadir, BW increased slightly faster in Holsteins compared with the other 2 breeds.

\section{Variance Components and Heritability of DMI, ECM, and BW Across Lactation}

The genetic variances for DMI tended to increase over lactation, whereas the permanent environmental variances were relatively stable over lactation. The residual variance for DMI was slightly higher at the beginning of lactation than later in the lactation. The 
heritability for DMI followed a similar trajectory over lactation for the 3 breeds and tended to increase from early lactation to later lactation stages (Figure 2). The heritability estimates ranged from 0.30 to 0.55 (mean $\mathrm{SE}=0.06)$ in Holstein cows across $44 \mathrm{wk}, 0.20$ to 0.48 (mean $\mathrm{SE}=0.08$ ) in RDC cows across $32 \mathrm{wk}$, and 0.17 to 0.52 (mean $\mathrm{SE}=0.10$ ) in Jersey cows across $44 \mathrm{wk}$. There was no significant breed difference in heritability for DMI $(P>0.05)$.

The genetic variance and the residual variance for ECM were higher at the beginning of lactation than at later lactation stages. The permanent environmental variance for ECM tended to increase over lactation.
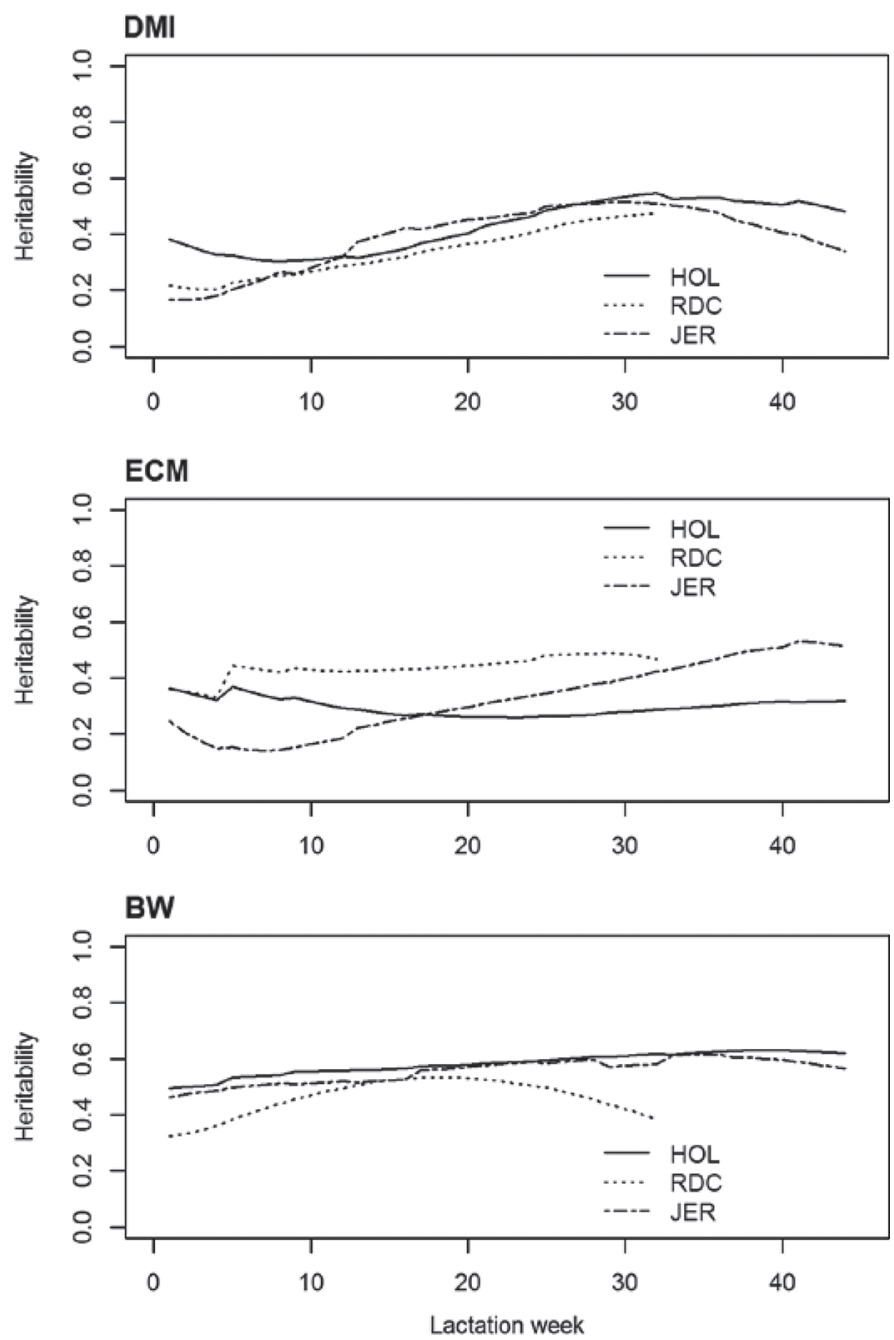

Figure 2. Heritability estimates of average daily DMI $(\mathrm{kg} / \mathrm{d})$, average daily ECM $(\mathrm{kg} / \mathrm{d})$, and average BW $(\mathrm{kg})$ in Holstein cows $(\mathrm{HOL})$ in 44 lactation weeks, Nordic Red cows (RDC) in 32 lactation weeks, and Jersey cows (JER) in 44 lactation weeks. The mean SE of heritability for DMI was 0.06, 0.08, and 0.10 in HOL, RDC, and JER, respectively. The mean SE of heritability for ECM was $0.06,0.08$, and 0.11 in HOL, RDC, and JER, respectively. The mean SE of heritability for $\mathrm{BW}$ was $0.08,0.10$, and 0.12 in $\mathrm{HOL}, \mathrm{RDC}$, and JER, respectively.
The heritability for ECM was moderate and tended to differ among breeds (Figure 2). However, differences in heritability estimates between breeds were not statistically significant in this study $(P>0.05)$. In Holstein and RDC cows, the heritability of ECM was relatively stable over lactation, ranging from 0.26 to 0.37 (mean $\mathrm{SE}=0.06)$ in Holstein cows across $44 \mathrm{wk}$ and from 0.33 to $0.49(\mathrm{SE}=0.08)$ in $\mathrm{RDC}$ cows across $32 \mathrm{wk}$. The heritability of ECM in Jersey cows showed a tendency of increase over lactation (from 0.14 to 0.53 ) but with fairly large standard errors (mean $\mathrm{SE}=0.11$ ).

The genetic variances for BW increased over lactation, whereas the permanent environmental variances were relatively stable over lactation. The residual variance for BW was higher at the beginning of lactation than at later lactation. The heritability for BW was higher than the heritability for DMI or ECM in all 3 breeds (Figure 2). Heritability for BW in Holstein and Jersey cows was fairly similar and stable across lactation, ranging from 0.49 to 0.63 in Holsteins (mean $\mathrm{SE}=$ 0.08 ) and 0.46 to 0.61 in Jerseys (mean $\mathrm{SE}=0.12$ ). The heritability of $\mathrm{BW}$ in RDC was from 0.32 to 0.53 over 32 wk (mean $\mathrm{SE}=0.10$ ), which was not significantly different from the heritability for BW in the Holstein or Jersey breeds $(P>0.05)$.

\section{Genetic Correlations Within DMI, ECM, and BW Across Lactation in 3 Dairy Breeds}

The genetic correlations between DMI at different lactation stages were less than unity (Figure 3A), indicating a genetic heterogeneity of feed intake across lactation. Low or even negative genetic correlations were observed for DMI between early lactation and the mid or late lactation stages, with the lowest values for Holstein, RDC, and Jersey of $0.0,-0.27$, and -0.15 , respectively. However, DMI within mid and late lactation stages generally showed a high genetic correlation. Compared with DMI, ECM showed less genetic heterogeneity across lactation in all breeds, although ECM in early and later lactation stages was still shown to be genetically different, with the lowest genetic correlation at approximately 0.5 (Figure 3B). In contrast, BW was shown to be the most consistent trait across lactation for all breeds, where BW in all weeks was highly correlated (Figure 3C). The genetic correlations for BW across lactation were higher than $0.74,0.61$, and 0.67 in Holstein, RDC, and Jersey cows, respectively.

\section{Genetic Correlations Between DMI, ECM, and BW in the Same Week of Lactation}

Genetic correlations between DMI, ECM, and BW changed over lactation (Figure 4), and the correlations 


\section{(A) DMI}
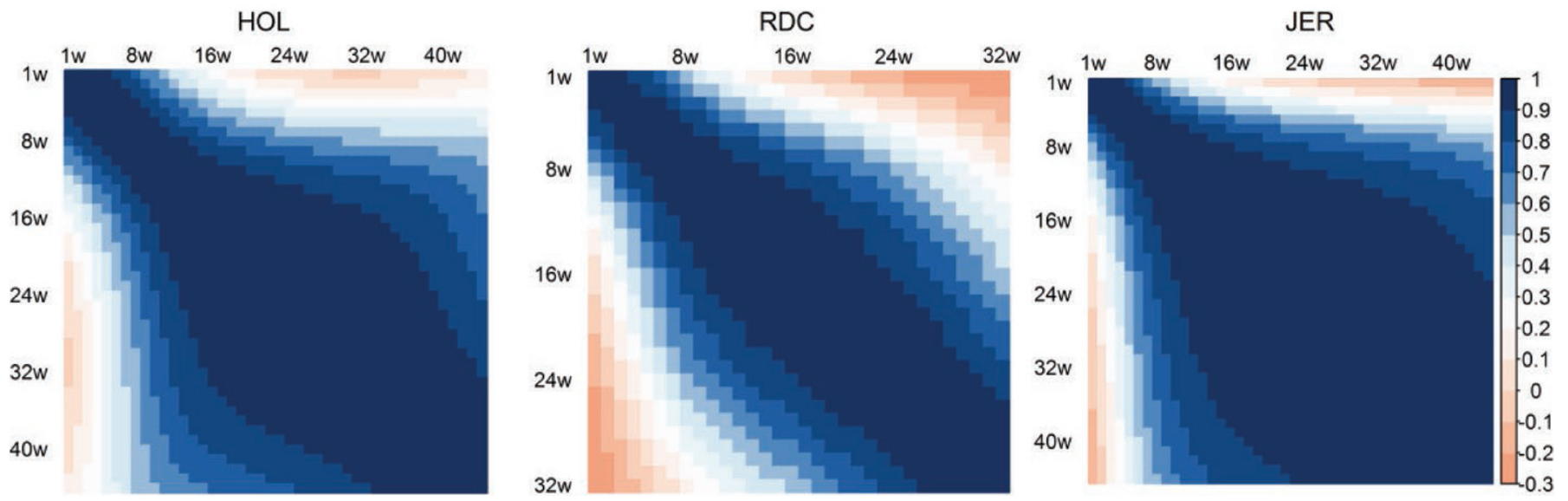

\section{(B) ECM}
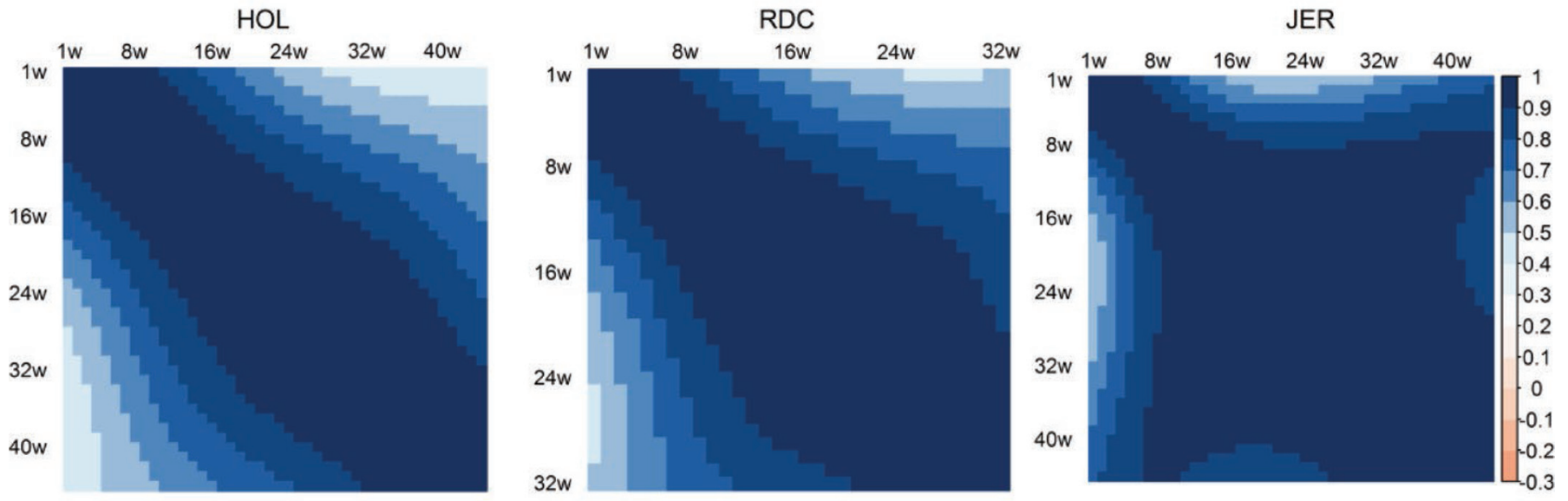

(C) BW
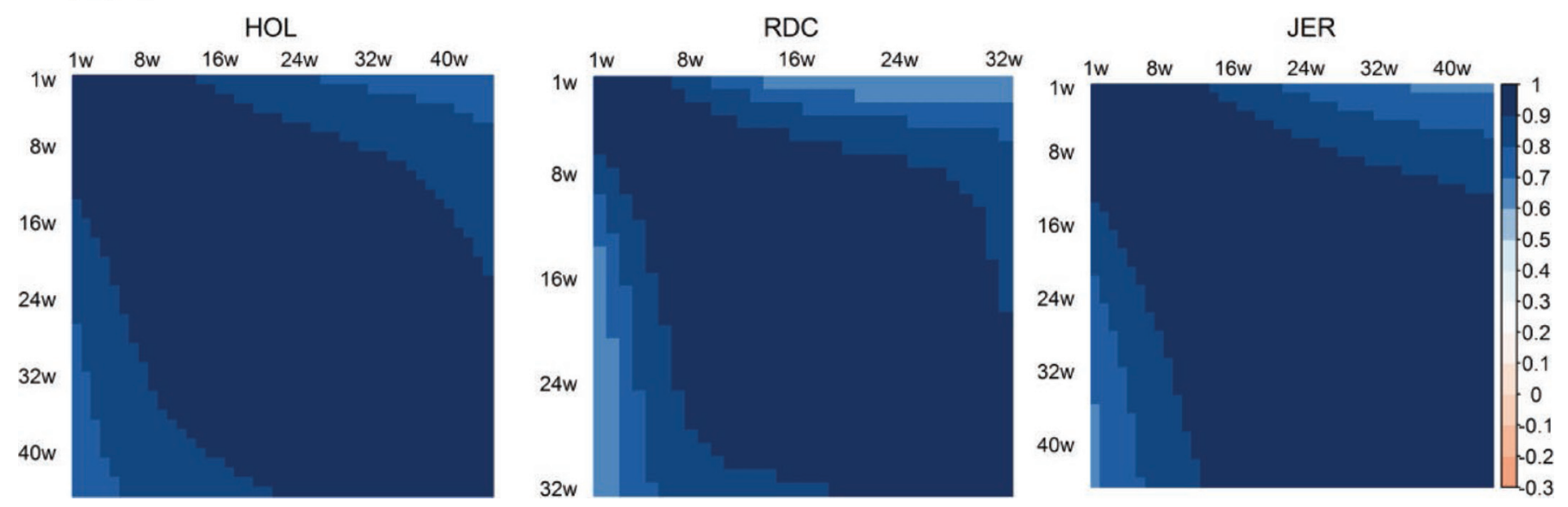

Figure 3. Genetic correlations for (A) DMI, (B) ECM, and (C) BW across 44 lactation weeks in Holstein cows (HOL), 32 lactation weeks in Nordic Red cows (RDC), and 44 lactation weeks (w) in Jersey cows (JER). The mean SE of genetic correlations for DMI was 0.09, 0.12, and 0.14 in HOL, RDC, and JER, respectively. The mean SE of genetic correlations for ECM was 0.09, 0.12, and 0.15 in HOL, RDC, and JER, respectively. The mean SE of genetic correlations for BW was 0.11, 0.13, and 0.17 in HOL, RDC, and JER, respectively. Color version available online. 
changed considerably more in early lactation compared with mid and late lactation. The trajectories of the correlations over lactation followed similar patterns in Holstein and RDC cows. In both breeds, cows' DMI and ECM were genetically weakly correlated at the beginning of lactation ( 0.24 for Holstein cows and 0.16 for RDC cows). After the beginning of lactation the correlation between DMI and ECM increased to 0.80 in wk 14 in Holstein cows, and it remained above 0.80 until the end of lactation. Similarly, in RDC cows, the genetic correlation between DMI and ECM continued to increase from early lactation and peaked in wk 16 with a correlation of 0.67 ; the correlation remained above 0.50 until wk 32 . The genetic correlation between cows' BW and ECM was low but positive at the beginning of lactation and decreased to become slightly negative in later lactation stages in both Holstein and RDC cows (Figure 4).

The genetic correlations between DMI and BW in Holstein and RDC cows had a very similar pattern over lactation (Figure 4). In both breeds, the correlation between DMI and BW increased from the beginning of lactation and peaked in wk 7 (with correlation at approximately 0.7), followed by a gradual decrease. The correlations remained positive during the entire lactation.

\section{DISCUSSION}

\section{Breed Similarity and Difference in DMI, ECM, and BW Across Lactation}

Phenotypic Observations. Cows of different breeds shared very similar patterns of lactation trajectories for phenotypic means of DMI, ECM, and BW. Immediately after calving, cows' average daily DMI and ECM both increased but at different rates. The average daily ECM increased sharply to peak at lactation wk 7 or 8 in all 3 breeds, whereas DMI reached a relatively high stable level no earlier than wk 11 and peaked even later. In dairy cattle, the slower increase in feed intake relative to milk yield in early lactation has been widely recognized, and it explained the deficiency of energy intake for milk production in early lactation as well as the body reserve mobilization of dairy cows (e.g., Berglund and Danell, 1987; Mao et al., 2004; Banos and Coffey, 2010). In our results, the observed BW loss in early lactation also reflected the occurrence of body reserve mobilization in all 3 dairy breeds, where the nadir of the BW curve appeared just before the ECM peaked, which was consistent with Søndergaard et al. (2002). In addition, cows of different breeds differed in the amount of BW loss from the beginning of lactation
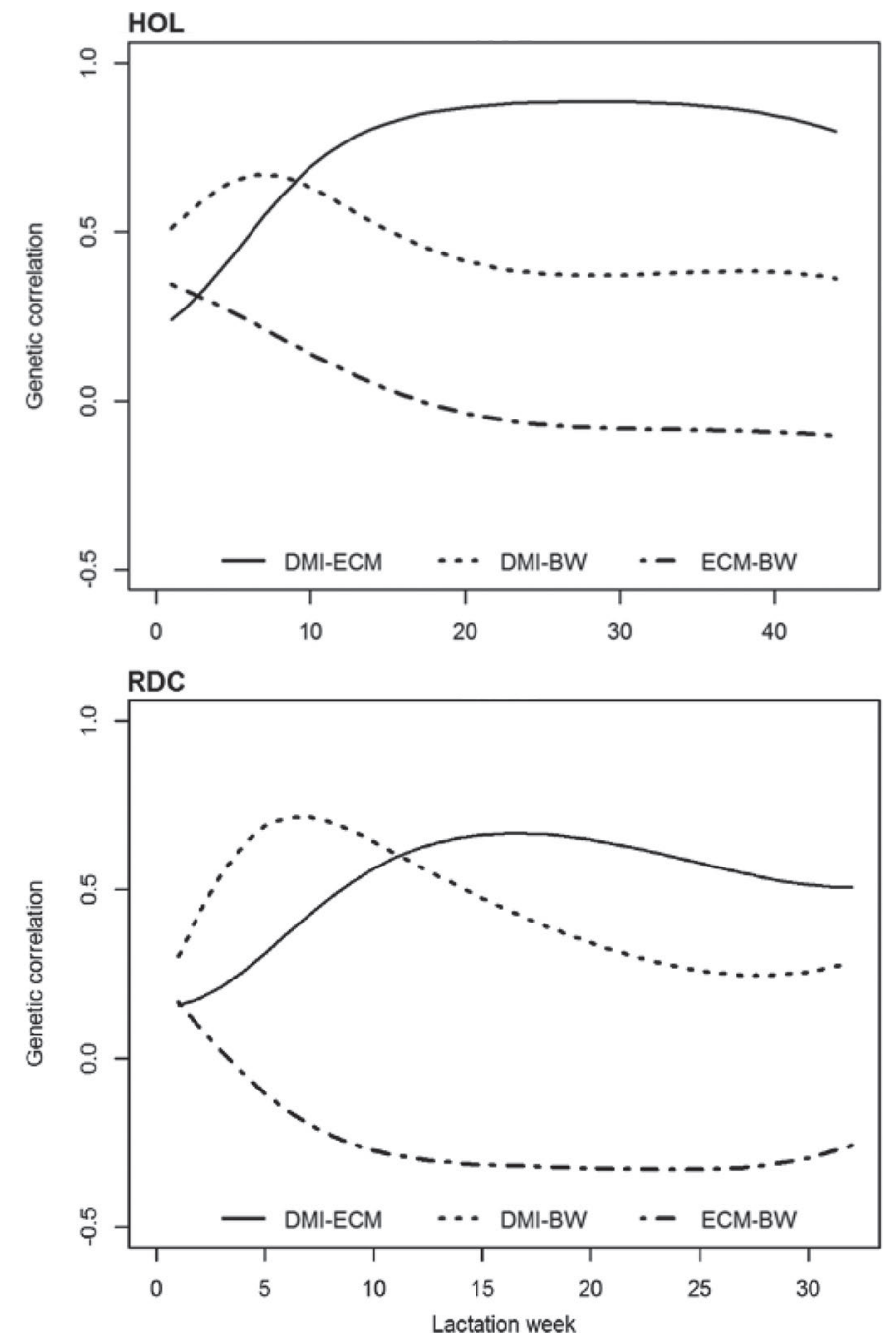

Figure 4. Genetic correlations among DMI, ECM, and BW in the same week of lactation in Holstein cows (HOL) across 44 lactation weeks and Nordic Red cows (RDC) across 32 lactation weeks. The mean SE of genetic correlations among DMI, ECM, and BW ranged from 0.09 to 0.11 in HOL cows and from 0.12 to 0.13 in RDC cows.

to the nadir of BW. Our study showed that Holstein cows and RDC cows had the highest and lowest BW loss, respectively, which was in agreement with Søndergaard et al. (2002).

Heritability. In most studies, including ours, the heritability estimates for feed intake in dairy cattle were moderate and in the same range as the heritability for milk yield, whereas heritability for BW was moderate to high and was higher than the heritability for DMI or yield (Karacaören et al., 2006; Vallimont et al., 2010; Spurlock et al., 2012). The ranges of heritability for DMI and ECM in this study agreed with those found in previous studies in Holstein cows (e.g., Spurlock et al., 2012; Berry et al., 2014; Manzanilla Pech et al., 2014b). 
The heritability estimate for ECM in RDC was higher in this study compared with the estimate of RDC by Liinamo et al. (2015). The latter study included only RDC cows from Finland, whereas in this study the RDC cows were from Denmark, Finland, and Sweden; of these, Danish RDC is highly genetically diverse, which might explain our findings. The heritability for DMI in Jerseys across the whole lactation period (44 wk) was to our knowledge first addressed in this study, where our results indicated very similar heritability for DMI in Jerseys and in Holsteins. In this study the data of Jersey cows were only from Danish herds because the Jersey breed is mainly populated in Denmark among Nordic countries. Further studies with larger data sets and from more data sources would be needed to obtain accurate estimates of genetic parameters for Jerseys and the breed similarity or difference between Jerseys and other dairy breeds.

\section{Genetic Heterogeneity of DMI, ECM, and BW Across Lactation}

Feed intake for dairy cows was genetically not the same trait across lactation, where the genetic correlations for DMI between early lactation and later lactation stages were found to be far from unity (e.g., Koenen and Veerkamp, 1998; Berry et al., 2007; Liinamo et al., 2012). Our study confirmed the genetic heterogeneity of DMI across lactation in Holstein and RDC dairy cows and observed the same phenomenon across lactation in Jersey cows. In all 3 breeds, DMI in middle and late lactation was generally highly correlated, in agreement with previous studies on the Holstein breed (Manzanilla Pech et al., 2014b).

In practice, the genetic heterogeneity of DMI across lactation needs to be carefully considered in any recording and selection strategy for FE. Due to the low genetic correlation for DMI between early and later lactation stages, DMI measurements in middle or late lactation cannot be strong predictors of DMI in early lactation and vice versa. To improve FE across lactation, it might be necessary to take DMI records from separate time points across all lactation stages. Apart from recording in middle and late lactation, a few DMI records in early lactation would also be recommended because DMI in early lactation is a different trait from DMI in later lactation. Manzanilla Pech et al. (2014a) estimated the accuracy of DMI breeding values using various recording schemes for DMI and found that higher accuracy was achieved when DMI was recorded at several lactation stages, when the number of measurements was limited across lactation (Manzanilla Pech et al., 2014a).

The genetic heterogeneity of DMI across lactation should also be considered when joining data from dif- ferent sources. To accumulate sufficient data for genetic and genomic evaluation for $\mathrm{FE}$, feed intake data were usually collected or combined from several herds and experiments within or across countries (e.g., Berry et al., 2014; de Haas et al., 2015). The joint data for FE could be heterogeneous in many aspects - for example, due to the difference in feeding systems, recording periods, or the number of repeated measurements (Hardie et al., 2015; Tempelman et al., 2015; Veerkamp et al., 2015). When joint data come from different lactation periods, the heterogeneity of feed intake across lactation stages may need to be considered before genetic evaluation. Data standardization might be needed in this situation to calibrate data from different lactation periods (Veerkamp et al., 2015). One method of standardization could be based on a random regression prediction of records for a cow using the cow's own repeated records and the covariance structure in the population (Banos et al., 2012; Berry et al., 2014; Veerkamp et al., 2015). Alternatively, feed intake from different lactation stages could also be defined as different traits, where a multiple-trait model could be applied in the genetic analyses.

Compared with feed intake, ECM showed much less genetic heterogeneity across lactation in all 3 breeds, although ECM at the beginning of lactation was still not exactly the same trait as ECM in mid or late lactation. Our findings are consistent with Hüttmann et al. (2009) and Manzanilla Pech et al. (2014b) for Holstein cows and with Liinamo et al. (2012) for RDC cows. The correlations for BW remained high across lactation in our study, in agreement with the findings of previous studies in Holstein cows (Koenen and Veerkamp, 1998; Hüttmann et al., 2009; Manzanilla Pech et al., 2014b) and RDC cows (Liinamo et al., 2012). Considering the high genetic consistency of BW across lactation, the number of repeated measurements of BW per cow across lactation could be reduced when recording BW in practice. However, a certain number of measurements of BW across lactation might still be needed to study cows' BW change.

\section{Dynamics of Genetic Correlations Between DMI, ECM, and BW Across Lactation}

First, it is important to realize that the observed relationships between DMI, ECM, and BW came from a complex metabolic system of lactation and the growth of dairy cattle. The genetic relationships between DMI, ECM, and BW do not stand alone in the system but rather are simultaneously linked to other body functions in the energy metabolic system (e.g., Hüttmann et al., 2009; Vallimont et al., 2010; Manzanilla-Pech et al., 2016). The energy intake and allocation at one 
time point affect several correlated responses that may also be expressed later. Therefore, several FE-related traits [e.g., feed intake, yield, BW, BCS, energy balance (EB), fertility] should be considered simultaneously to avoid the perceived gain from improvement of one trait being counteracted by undesirable correlated responses in other traits (Veerkamp, 1998). Additionally, changes in the relationship between FE-related traits over lactation should be considered, factoring in the potential genetic heterogeneity of these traits across lactation (Hüttmann et al., 2009; Liinamo et al., 2012; Manzanilla Pech et al., 2014b). According to our results, the genetic correlations between DMI, ECM, and BW were shown to be very different between early lactation and mid and late lactation, indicating differences in the metabolic mechanism for milk production between early lactation and mid and late lactation.

The feed intake of dairy cows was found to be positively correlated with milk yield when accumulated over the entire lactation period (Veerkamp, 1998; Vallimont et al., 2010; Manzanilla-Pech et al., 2016), indicating that selection for milk yield would concurrently increase DMI. However, recent studies, including ours, showed that the genetic correlation between DMI and ECM in early lactation is low (Hüttmann et al., 2009; Spurlock et al., 2012) or even slightly negative (Karacaören et al., 2006; Manzanilla Pech et al., 2014b). The low correlation between DMI and ECM in early lactation indicated that selection for higher milk yield may lead to only a small genetic change in cows' feed intake in the initial period of lactation and vice versa. This implies an increased negative EB in the case of exclusive breeding for milk yield (Hüttmann et al., 2009). A negative EB has been reported to have an unfavorable genetic correlation with dairy cattle fertility and health (Collard et al., 2000; Veerkamp et al., 2000; Banos and Coffey, 2009). In this case, EB itself or an EB indicator trait (i.e., BCS) for early lactation should be considered in dairy cattle breeding to avoid a more severe negative EB when selecting for higher yield or FE (e.g., Veerkamp, 1998; Coffey et al., 2002; Liinamo et al., 2012).

The genetic correlation between cows' DMI and BW was found to be higher than the correlation between DMI and milk yield at the beginning of lactation (Liinamo et al., 2012; Spurlock et al., 2012; Manzanilla Pech et al., 2014b). However, the genetic correlation between DMI and milk yield increased during early lactation, and DMI became highly correlated with milk yield (above 0.7) in middle and late lactation (Hüttmann et al., 2009; Spurlock et al., 2012; Manzanilla Pech et al., 2014b). The significant increase in the genetic relationship between feed intake and milk yield from early to middle lactation was also observed in $\mathrm{Li}$ et al. (2017), who found a significant increase in the partial efficiency of feed intake on milk yield from the beginning of lactation to approximately lactation wk 12 . In contrast, the genetic correlation between DMI and BW was relatively stable and positive throughout the entire lactation period (Liinamo et al., 2012; Manzanilla Pech et al., 2014b), indicating that bigger cows tend to have higher feed intake due to the higher energy required for body maintenance.

The low but positive genetic correlation between ECM and BW at the beginning of lactation - seen in our results and some previous studies (Karacaören et al., 2006; Spurlock et al., 2012; Manzanilla Pech et al., 2014b) - indicated the capacity of larger cows with higher milk yield in the initial part of lactation. However, after the initial lactation weeks, the rapid decrease of the correlation between BW and milk yield was also seen in previous studies (Karacaören et al., 2006; Hüttmann et al., 2009; Liinamo et al., 2012). The change in genetic correlation between milk yield and BW across lactation could be due to the contribution of body tissue mobilization, where milk yield and BW are both closely associated with body tissue mobilization (Veerkamp, 1998). Therefore, traits related to body tissue mobilization (e.g., BCS) could be important for understanding the genetic relationships between FErelated traits, especially for early lactation.

\section{CONCLUSIONS}

The general patterns of genetic parameters for DMI, ECM, and BW across lactation were similar across dairy cattle breeds (Holstein, RDC, and Jersey). Feed intake was genetically not the same trait across lactation stages, especially between the early and later lactation stages. Measurement of feed intake is recommended to be spread over different lactation stages from the entire lactation, or at least from both early and middle lactation. Compared with feed intake, ECM and BW showed much less genetic heterogeneity across lactation in all 3 breeds. The genetic correlations between DMI, ECM, and $\mathrm{BW}$ changed across lactation, but the patterns of change in the genetic correlations between DMI, ECM, and BW were very similar between breeds.

\section{ACKNOWLEDGMENTS}

This study was part of the joint project "Feed Utilization in Nordic Cattle (FUNC)" among Nordic countries (Denmark, Finland, Norway, and Sweden). The authors acknowledge the Danish Cattle Research Center (Foulum, Denmark), Natural Resources Institute Finland 
(Jokioinen, Finland), and Swedish University of Agricultural Sciences (Uppsala, Sweden) for collaborating in joining the data. The authors also acknowledge the Swedish Farmers' Foundation for Agricultural Research (Stockholm, Sweden) for its financial support. The first author is enrolled in the Erasmus Mundus European Graduate School in Animal Breeding and Genetics (EGS-ABG; http://www.egsabg.eu/).

\section{REFERENCES}

Banos, G., and M. P. Coffey. 2010. Genetic association between body energy measured throughout lactation and fertility in dairy cattle. Animal 4:189-199.

Banos, G., M. P. Coffey, R. F. Veerkamp, D. P. Berry, and E. Wall. 2012. Merging and characterising phenotypic data on conventional and rare traits from dairy cattle experimental resources in three countries. Animal 6:1040-1048.

Berglund, B., and B. Danell. 1987. Live weight changes, feed consumption, milk yield and energy balance in dairy cattle during the first period of lactation. Acta Agric. Scand. 37:495-509.

Berry, D. P., M. P. Coffey, J. E. Pryce, Y. de Haas, P. Løvendahl, N. Krattenmacher, J. J. Crowley, Z. Wang, D. Spurlock, K. Weigel, K. Macdonald, and R. F. Veerkamp. 2014. International genetic evaluations for feed intake in dairy cattle through the collation of data from multiple sources. J. Dairy Sci. 97:3894-3905.

Berry, D. P., B. Horan, M. O'Donovan, F. Buckley, E. Kennedy, M. McEvoy, and P. Dillon. 2007. Genetics of grass dry matter intake, energy balance, and digestibility in grazing Irish dairy cows. J. Dairy Sci. 90:4835-4845.

Buttchereit, N., E. Stamer, W. Junge, and G. Thaller. 2011. Short communication: Genetic relationships among daily energy balance, feed intake, body condition score, and fat to protein ratio of milk in dairy cows. J. Dairy Sci. 94:1586-1591.

Byskov, M. V., A. Fogh, and P. Løvendahl. 2017. Genetic parameters of rumination time and feed efficiency traits in primiparous Holstein cows under research and commercial conditions. J. Dairy Sci. 100:9635-9642.

Coffey, M. P., G. Simm, and S. Brotherstone. 2002. Energy balance profiles for the first three lactations of dairy cows estimated using random regression. J. Dairy Sci. 85:2669-2678.

Collard, B. L., P. J. Boettcher, J. C. Dekkers, D. Petitclerc, and L. R. Schaeffer. 2000. Relationships between energy balance and health traits of dairy cattle in early lactation. J. Dairy Sci. 83:2683-2690.

de Haas, Y., J. E. Pryce, M. P. L. Calus, E. Wall, D. P. Berry, P. Løvendahl, N. Krattenmacher, F. Miglior, K. Weigel, D. Spurlock, K. a. Macdonald, B. Hulsegge, and R. F. Veerkamp. 2015. Genomic prediction of dry matter intake in dairy cattle from an international data set consisting of research herds in Europe, North America, and Australasia. J. Dairy Sci. 98:6522-6534.

Hardie, L. C., L. E. Armentano, R. D. Shaver, M. J. VandeHaar, D. M. Spurlock, C. Yao, S. J. Bertics, F. E. Contreras-Govea, and K. A. Weigel. 2015. Considerations when combining data from multiple nutrition experiments to estimate genetic parameters for feed efficiency. J. Dairy Sci. 98:2727-2737.

Hüttmann, H., E. Stamer, W. Junge, G. Thaller, and E. Kalm. 2009 Analysis of feed intake and energy balance of high-yielding first lactating Holstein cows with fixed and random regression models. Animal 3:181-188.

Jensen, J., E. A. Mäntysaari, P. Madsen, and R. Thompson. 1997. Residual maximum likelihood estimation of (co)variance components in multivariate mixed linear models using average information. J. Indian Soc. Agric. Stat. 49:215-236.

Karacaören, B., F. Jaffrézic, and H. N. Kadarmideen. 2006. Genetic parameters for functional traits in dairy cattle from daily random regression models. J. Dairy Sci. 89:791-798.

Koenen, E. P. C., and R. F. Veerkamp. 1998. Genetic covariance functions for live weight, condition score, and dry-matter intake mea- sured at different lactation stages of Holstein Friesian heifers. Livest. Prod. Sci. 57:67-77.

Korver, S. 1988. Genetic aspects of feed intake and feed efficiency in dairy cattle: A review. Livest. Prod. Sci. 20:1-13.

Li, B., B. Berglund, W. F. Fikse, J. Lassen, M. H. Lidauer, P. Mäntysaari, and P. Løvendahl. 2017. Neglect of lactation stage leads to naive assessment of residual feed intake in dairy cattle. J. Dairy Sci. 100:9076-9084.

Li, B., W. F. Fikse, J. Lassen, M. H. Lidauer, P. Løvendahl, P. Mäntysaari, and B. Berglund. 2016. Genetic parameters for dry matter intake in primiparous Holstein, Nordic Red, and Jersey cows in the first half of lactation. J. Dairy Sci. 99:7232-7239.

Liinamo, A.-E., P. Mantysaari, M. H. Lidauer, and E. A. Mantysaari. 2015. Genetic parameters for residual energy intake and energy conversion efficiency in Nordic Red dairy cattle. Acta Agric. Scand. Sect. A Anim. Sci. 65:63-72.

Liinamo, A.-E., P. Mäntysaari, and E. A. Mäntysaari. 2012. Short communication: Genetic parameters for feed intake, production, and extent of negative energy balance in Nordic Red dairy cattle. J. Dairy Sci. 95:6788-6794.

Løvendahl, P., and M. G. G. Chagunda. 2011. Covariance among milking frequency, milk yield, and milk composition from automatically milked cows. J. Dairy Sci. 94:5381-5392.

Løvendahl, P., C. Ridder, and N. C. Friggens. 2010. Limits to prediction of energy balance from milk composition measures at individual cow level. J. Dairy Sci. 93:1998-2006.

Madsen, P., and J. Jensen. 2013. DMU-A Package for Analyzing Multivariate Mixed Models in Quantitative Genetics and Genomics. Center for Quantitative Genetics and Genomics (QGG), Aarhus University, Tjele, Denmark.

Mäntysaari, P., A.-E. Liinamo, and E. A. Mäntysaari. 2012. Energy efficiency and its relationship with milk, body, and intake traits and energy status among primiparous Nordic Red dairy cattle. J. Dairy Sci. 95:3200-3211.

Mäntysaari, P., and E. A. Mäntysaari. 2015. Modeling of daily body weights and body weight changes of Nordic Red cows. J. Dairy Sci 98:6992-7002. https://doi.org/10.3168/jds.2015-9541.

Mäntysaari, P., J. Nousiainen, and P. Huhtanen. 2003. The effect of constant or variable forage to concentrate ratio in total mixed ration on performance of primiparous dairy cows. Livest. Prod. Sci. $82: 27-37$.

Manzanilla Pech, C. I. V., R. F. Veerkamp, M. P. L. Calus, J. E. Pryce, and Y. de Haas. 2014a. Genetic parameters and accuracy of recording dry matter intake in first parity Holstein-Friesian cows. Page 554 in Proceedings of the 10th WCGALP Conference, Vancouver, BC, Canada. Am. Soc. Anim. Sci., Champaign, IL.

Manzanilla Pech, C. I. V., R. F. Veerkamp, M. P. L. Calus, R. Zom, A. van Knegsel, J. E. Pryce, and Y. De Haas. 2014b. Genetic parameters across lactation for feed intake, fat- and protein-corrected milk, and liveweight in first-parity Holstein cattle. J. Dairy Sci. 97:5851-5862.

Manzanilla-Pech, C. I. V., R. F. Veerkamp, R. J. Tempelman, M. L. van Pelt, K. A. Weigel, M. VandeHaar, T. J. Lawlor, D. M. Spurlock, L. E. Armentano, C. R. Staples, M. Hanigan, and Y. De Haas. 2016. Genetic parameters between feed-intake-related traits and conformation in 2 separate dairy populations - the Netherlands and United States. J. Dairy Sci. 99:443-457.

Mao, I. L., K. Sloniewski, P. Madsen, and J. Jensen. 2004. Changes in body condition score and in its genetic variation during lactation. Livest. Prod. Sci. 89:55-65.

Nielsen, H. M., N. C. Friggens, P. Løvendahl, J. Jensen, and K. L. Ingvartsen. 2003. Influence of breed, parity, and stage of lactation on lactational performance and relationship between body fatness and live weight. Livest. Prod. Sci. 79:119-133.

Sjaunja, L. O., L. Baevre, L. Junkkarinen, J. Pedersen, and J. Setälä. 1990. A Nordic proposal for an energy corrected milk (ECM) formula. Pages 156-157 in Proceedings of the 27th biennial session of the International Committee for Animal Recording (ICAR), Paris, France. Pudoc, Wageningen, the Netherlands.

Søndergaard, E., M. K. Sørensen, I. L. Mao, and J. Jensen. 2002. Genetic parameters of production, feed intake, body weight, body 
composition, and udder health in lactating dairy cows. Livest. Prod. Sci. 77:23-34.

Spurlock, D. M., J. C. M. Dekkers, R. Fernando, D. A. Koltes, and A. Wolc. 2012. Genetic parameters for energy balance, feed efficiency, and related traits in Holstein cattle. J. Dairy Sci. 95:5393-5402.

Tempelman, R. J., D. M. Spurlock, M. Coffey, R. F. Veerkamp, L. E. Armentano, K. A. Weigel, Y. de Haas, C. R. Staples, E. E. Connor, Y. Lu, and M. J. VandeHaar. 2015. Heterogeneity in genetic and nongenetic variation and energy sink relationships for residual feed intake across research stations and countries. J. Dairy Sci. 98:2013-2026.

Tetens, J., G. Thaller, and N. Krattenmacher. 2014. Genetic and genomic dissection of dry matter intake at different lactation stages in primiparous Holstein cows. J. Dairy Sci. 97:520-531.

Vallimont, J. E., C. D. Dechow, J. M. Daubert, M. W. Dekleva, J. W. Blum, C. M. Barlieb, W. Liu, G. A. Varga, A. J. Heinrichs, and C. R. Baumrucker. 2010. Genetic parameters of feed intake, production, body weight, body condition score, and selected type traits of Holstein cows in commercial tie-stall barns. J. Dairy Sci. 93:4892-4901.

Veerkamp, R. F. 1998. Selection for economic efficiency of dairy cattle using information on live weight and feed intake: A review. J. Dairy Sci. 81:1109-1119.

Veerkamp, R. F., Y. de Haas, J. E. Pryce, M. P. Coffey, D. M. Spurlock, and M. J. VandeHaar. 2015. Guidelines to measure individual feed intake of dairy cows for genomic and genetic evaluations. Page 191 in Proceedings of the ICAR Technical Meeting, Krakow, Poland. International Committee for Animal Recording, Rome, Italy. Veerkamp, R. F., J. K. Oldenbroek, H. J. Van Der Gaast, and J. H. J. Van Der Werf. 2000. Genetic correlation between days until start of luteal activity and milk yield, energy balance, and live weights. J. Dairy Sci. 83:577-583.

Veerkamp, R. F., and R. Thompson. 1999. A covariance function for feed intake, live weight, and milk yield estimated using a random regression model. J. Dairy Sci. 82:1565-1573. 